\title{
Factors Affecting Continued Use of Subcutaneous Depot Medroxyprogesterone Acetate (DMPA-SC): A Secondary Analysis of a 1-Year Randomized Trial in Malawi
}

\author{
Holly M. Burke, ${ }^{a}$ Mario Chen, ${ }^{a}$ Mercy Buluzi, ${ }^{b}$ Rachael Fuchs, ${ }^{a}$ Silver Wevill, ${ }^{a}$ Lalitha Venkatasubramanian, ${ }^{a}$ \\ Leila Dal Santo, a Bagrey Ngwirab
}

Community health workers can adequately provide DMPA-SC directly or train women on self-injection.

\section{ABSTRACT}

Objective: To assess the supply- and demand-side factors influencing continued use of the injectable contraceptive subcutaneous depot medroxyprogesterone acetate (DMPA-SC).

Methods: We conducted a 12-month randomized controlled trial in Malawi to measure DMPA-SC continuation rates. A total of 731 women presenting to clinic-based providers (CBPs) at 6 Ministry of Health clinics or to community health workers (CHWs) in rural communities were randomized to receive DMPA-SC administered by a provider or be trained to self-inject DMPA-SC. Data collectors contacted women after the reinjection window at 3,6, and 9 months to collect data on discontinuation and women's experiences. Twelve months after enrollment or at early discontinuation, women had their final interview, including pregnancy testing. We compared continuation, pregnancy, and safety by whether DMPA-SC or self-injection training was provided by $\mathrm{CHWs}$ versus CBPs. We also conducted an exploratory analysis assessing the association between women's sociodemographic factors and the risk for discontinuation using stratified Cox proportional hazards models.

Findings: The type of provider did not seem to influence continuation, pregnancy, or safety. As reported previously, women in the selfinjection group were significantly less likely to discontinue the method compared with women in the provider-administered group (hazard ratio, $0.43 ; P<.001)$. The risk for discontinuation was also different among health facility catchment sites $(P<.001)$. No other assessed sociodemographic factors were found to significantly influence the risk for discontinuation.

Conclusions: Public-sector CHWs can safely and effectively provide DMPA-SC and train women to self-inject DMPA-SC in low-resource settings. DMPA-SC continuation did not seem to be influenced by the type of provider, whether CBP or CHW, or women's sociodemographic characteristics.

\section{BACKGROUND}

$I^{2}$ njectable contraceptives are increasingly popular in low-and middle-income countries and are the predominant modern method used by women in sub-Saharan Africa. ${ }^{1}$ In Malawi, the use of modern contraceptive methods by married women has increased from $7 \%$ in 1992 to 58\% in 2015-2016; however, unmet need for family planning is considerable at $19 \%{ }^{2}$ Injectables are the most commonly used method-of married women in Malawi who use a modern method of contraception, $30 \%$ use injectables. Despite their high use, discontinuation rates for injectables are high; $41 \%$ of women of reproductive age have reported discontinuing the method in the first year. ${ }^{2}$ In addition to method-related concerns, travel distance to a nearby health center-over $80 \%$ of

\footnotetext{
${ }^{a}$ FHI 360, Durham, NC, USA.

${ }^{b}$ College of Medicine, University of Malawi, Blantyre, Malawi.

Correspondence to Holly M. Burke (hburke@fhi360.org).
}

the approximately 17 million people in Malawi live in rural areas $^{3}$-and frequent contraceptive stock-outs are common barriers to use and continuation. ${ }^{4}$

The World Health Organization (WHO) has endorsed task sharing as a strategy to bridge the human resource gap in the provision of reproductive health services in low-income countries, noting that "task sharing is envisioned to create a more rational distribution of tasks and responsibilities among cadres of health workers to improve access and cost-effectiveness." When clinicbased providers (CBPs) share tasks with CHWs, the workload of CBPs is reduced, which allows more time for them to provide higher-level care and curative services while increasing access to contraception for women living in hard-to-reach places-thereby helping to address their unmet family planning needs. ${ }^{6}$

Malawi's program for community-based access to injectable contraception started with a pilot in $2008 .^{7}$ CHWs in Malawi (also called health surveillance 
assistants) provide health services to catchment areas of approximately 1,000 people each; they are the lowest level of paid government workers. ${ }^{8}$ They have completed secondary school and received 12 weeks of training - the first 8 weeks are in a classroom, followed by 4 weeks of practical training. As is the case in many other low- and middle-income countries, CHWs in Malawi administer intramuscular depot medroxyprogesterone acetate (DMPA-IM) to clients in community settings as part of the family planning method mix they offer.

A subcutaneous (SC) version of DMPA is delivered in a prefilled, auto-disabled Uniject injection system (Sayana Press with $104 \mathrm{mg}$ of medroxyprogesterone acetate in $0.65 \mathrm{~mL}$ suspension for injection). DMPA-SC is steadily gaining popularity among family planning users and providers in subSaharan Africa as an easy-to-use and accessible contraceptive option. Studies in Senegal and Uganda found that family planning providers preferred the subcutaneous version over the intramuscular formation-providers indicated that DMPASC was easier and faster to administer, would decrease stock-outs (due to its all-in-one presentation compared with DMPA-IM, which requires a vial and syringe that may become separated), and would be less painful and therefore preferable for women. ${ }^{9}$ Research has also demonstrated that CHWs can safely provide DMPA-SC in community settings. ${ }^{10,11}$ Moreover, given the simplified delivery system and subcutaneous administration route, a growing body of evidence underscores the feasibility, acceptability, and efficacy of self-injection of DMPA-SC. Self-injection was found to be acceptable and feasible in Senegal and Uganda. ${ }^{12,13}$ In the current study, a randomized trial recently conducted in Malawi, self-injection improved 12-month continuation rates significantly compared with provider-administered DMPA-SC, by more than $50 \%$ (the primary results are reported elsewhere). ${ }^{11}$ In the Malawi study, both CHWs and CBPs were trained to administer injections and to teach women to self-inject.

The recent trial in Malawi demonstrated that public-sector family planning providers, including CHWs, can safely provide DMPA-SC and train women to self-inject. However, little is known about whether and how outcomes-including continuation, adverse events, side effects, and pregnancy-vary by supply-side factors such as the type of family planning provider ( $\mathrm{CHW}$ or CBP) who provides DMPA-SC or self-injection training to women. CBPs in the trial were government nurses and midwives with more health care training than the CHWs, which may influence the quality of services provided. Furthermore, the knowledge base is nascent regarding demand-side factors such as the sociodemographic characteristics of women that may influence 12-month DMPA-SC continuation, especially for selfadministered DMPA-SC. The numerous studies that have been conducted to assess determinants of continuation of DMPA-IM indicate that women who receive complete and accurate information on possible side effects are more likely to continue using DMPA ${ }^{14-18}$ and that side effects, especially menstrual disturbances, are an important factor influencing discontinuation. ${ }^{16,19-23}$ In contrast, age, marital status, educational level, and parity have not been shown to significantly impact DMPA-IM continuation. 1,17,24,25

It is unclear how factors influencing continuation of IM and SC formulations will differ, especially when DMPA-SC is self-administered. Two nonrandomized cohort studies in Burkina Faso and Uganda found no difference in continuation rates between DMAP-SC and DMPA-IM when both were administered by CBPs, but findings showed that increased age and partners' acceptance of family planning increased DMPA continuation in Burkina Faso (no other variables tested with the Uganda data were statistically different). ${ }^{26}$ In acceptability trials conducted with DMPA-IM clients in Senegal and Uganda, most clients preferred DMPA-SC after trying it; the most common reason for this preference was that clients perceived fewer side effects from DMPA-SC compared with DMPA-IM, ${ }^{10}$ though previous safety and effectiveness trials have not demonstrated this difference. ${ }^{27,28}$ A recent nonrandomized cohort study in Senegal also observed fewer side effects among clients who self-injected DMPA-SC compared with those who received DMPA-IM from a CBP. ${ }^{29}$

Given the limited research on factors affecting continued use of DMPA-SC, especially for selfinjected DMPA-SC, the aim of this article is to assess the influence of selected supply- and demand-side factors on continued use of DMPASC among Malawian women enrolled in a yearlong randomized controlled trial. These data can be used to inform task-sharing decisions and optimize service delivery in Malawi and other lowresource settings.

\section{METHODS}

We used data collected as part of a randomized controlled trial we conducted to compare

\section{A growing body of evidence shows that self-injection of DMPA-SC is feasible and acceptable and that CHWs can safely provide it.}


continuation rates between women who selfinject DMPA-SC and women who receive the same product from a provider. The trial was conducted from September 2015 to February 2017 in 6 Ministry of Health clinics and surrounding communities in rural Mangochi District, Malawi. During the trial, CBPs and CHWs randomized 731 women seeking family planning services to either receive DMPA-SC administered by the provider or be trained to self-inject DMPA-SC. Eligible participants were ages 18 to 40 years, in self-reported good general health, able to understand and willing to sign an informed consent document, willing to give contact information for follow-up, willing to have follow-up visits or interviews, willing to be randomized to the selfinjection arm or provider-administered injection group, not pregnant according to WHO guidelines, and able to meet eligibility criteria for receiving DMPA per WHO medical eligibility criteria. ${ }^{30-32}$ Women in the self-injection group who successfully self-injected at enrollment (assessed by the provider) received 3 doses of DMPA-SC to take home for subsequent self-injections, whereas women in the provider-administered injection group were asked to return to the provider for injections at 3, 6, and 9 months post-enrollment. Data collectors (not providers) contacted women after the reinjection window at 3, 6, and 9 months to collect data on discontinuation and women's experiences. Twelve months after enrollment or at early discontinuation, women had their final interview, including pregnancy testing. Neither participants nor study staff were blinded after randomization; however, the statistical team remained blinded until key decisions for the primary analysis were made. A detailed description of the methods of the randomized controlled trial has been published elsewhere. ${ }^{11}$

Our primary outcome was DMPA-SC discontinuation. Women were considered discontinuers if they did not report receiving an injection within the allowable window of time (12 to 14 weeks after the last injection, according to Sayana Press guidelines). Given that reinjection provides 3 months of protection, participants without a DMPA-SC injection within the window or who were lost to follow-up were considered to have discontinued 3 months after the previous injection. Those who had not discontinued by 12 months were censored at 12 months, when the study ended.

We collected data on adverse events, side effects, and pregnancies occurring throughout the 12-month follow-up. In this article, we report outcomes comparing women assisted by CBPs or CHWs. The analysis of safety data included only participants who successfully received or administered a DMPA-SC injection after randomization.

We estimated Kaplan-Meier cumulative probabilities of contraceptive continuation coverage (with 95\% confidence interval [CI] at 3, 6, and 9 months) by provider type and compared the distribution of continuation between these groups using a log-rank test stratified by site using a .05 significance level for a 2 -sided comparison. We present these results separately by the original randomization group (i.e., self-injection and provider-administered DMPA-SC) since the primary results demonstrated a large treatment effect on continuation. ${ }^{11}$ We also provide discontinuation incidence estimates and incidence rate ratio with $95 \%$ CI comparing the 2 provider types.

We also assessed factors that could potentially influence DMPA-SC discontinuation using Cox proportional hazards models with each of the following covariates: treatment group (i.e., selfinjection or provider-administered DMPA-SC), site (i.e., the health facility catchment area where the participant was enrolled), woman's age, marital status, whether she works outside the home, parity, education, religion, previous experience with contraceptives and injectable contraceptives, and whether a CBP or CHW provided DMPA-SC or self-injection training at enrollment.

We assessed each covariate separately and planned to include all covariates found significant at the .05 level in the univariate models in a multivariable model. Except for when we analyzed the effect of site specifically, site was used as a stratification variable in the models as consistent with the randomization scheme. Hazard ratios for discontinuation and $95 \%$ CI were provided for each covariate modeled.

The study protocol was reviewed and approved by the Protection of Human Subjects Committee at FHI 360, Durham, NC, USA, as well as the College of Medicine Research and Ethics Committee, University of Malawi. All study staff completed training on research ethics, the protocol, and informed consent administration. All trial participants provided their informed consent to participate. The trial was registered with ClinicalTrials. gov (NCT02293694).

\section{口 RESULTS}

Participants' sociodemographic characteristics are shown in Table 1 . Over $70 \%$ were enrolled in the study by a CHW. The mean age was 27 years, and 
TABLE 1. Baseline Sociodemographic Characteristics of Participants, September 2015 to February 2017, Mangochi District, Malawi (N=731)

\begin{tabular}{|c|c|}
\hline Characteristic & Value \\
\hline \multicolumn{2}{|l|}{ Provider type at enrollment, No. (\%) } \\
\hline Clinic-based & $205(28.0)$ \\
\hline Community health worker & $526(72.0)$ \\
\hline \multicolumn{2}{|l|}{ Age group, years, No. (\%) } \\
\hline $18-24$ & $264(36.1)$ \\
\hline $25-29$ & $238(32.6)$ \\
\hline $30-35$ & $184(25.2)$ \\
\hline$>35$ & $45(6.2)$ \\
\hline Age, years, mean (SD) & $26.9(5.2)$ \\
\hline \multicolumn{2}{|l|}{ Education, No. (\%) } \\
\hline No school/less than primary school & $545(74.6)$ \\
\hline Completed primary school or higher & $185(25.3)$ \\
\hline No response & $1(0.1)$ \\
\hline \multicolumn{2}{|l|}{ Religion, No. (\%) } \\
\hline Christian & $310(42.4)$ \\
\hline Muslim & $418(57.2)$ \\
\hline None & $1(0.1)$ \\
\hline No response & $2(0.3)$ \\
\hline \multicolumn{2}{|l|}{ Married or has regular sexual partner, No. (\%) } \\
\hline Not married and no regular sexual partner & $25(3.4)$ \\
\hline Married or regular sexual partner & 705 (96.4) \\
\hline No response & $1(0.1)$ \\
\hline \multicolumn{2}{|c|}{ Husband/partner knows respondent receiving family planning today, among those with partner, ${ }^{a}$ No. $(\%)$} \\
\hline No & $137(20.1)$ \\
\hline Yes & $522(76.8)$ \\
\hline Don't know & $13(1.9)$ \\
\hline No response & $8(1.2)$ \\
\hline \multicolumn{2}{|l|}{ Ever given birth, No. (\%) } \\
\hline No & $5(0.7)$ \\
\hline Yes & 725 (99.2) \\
\hline No response & $1(0.1)$ \\
\hline \multicolumn{2}{|l|}{ Number of living children, among those who gave birth, No. $(\%)$} \\
\hline Less than 3 living children & $321(44.3)$ \\
\hline 3 or more living children & $404(55.7)$ \\
\hline Number of living children, among those who gave birth, mean (SD) & $3.0(1.64)$ \\
\hline
\end{tabular}


TABLE 1. Continued

\begin{tabular}{|c|c|}
\hline Characteristic & Value \\
\hline \multicolumn{2}{|c|}{ Would like to have a/another child, No. (\%) } \\
\hline No & $182(24.9)$ \\
\hline Yes & $529(72.4)$ \\
\hline Don't know & $17(2.3)$ \\
\hline No response & $3(0.4)$ \\
\hline \multicolumn{2}{|c|}{ Ever used contraception, No. (\%) } \\
\hline No & $47(6.4)$ \\
\hline Yes & $679(92.9)$ \\
\hline No response & $5(0.7)$ \\
\hline \multicolumn{2}{|c|}{ Ever used injectables, among those who ever used contraception, No. (\%) } \\
\hline No & $21(3.1)$ \\
\hline Yes & $657(96.8)$ \\
\hline No response & $1(0.1)$ \\
\hline
\end{tabular}

$75 \%$ had no schooling or did not complete primary school. Over half were Muslim. Almost all were married or had a sexual partner, and $20 \%$ said that their husband or partner did not know about their appointment to receive family planning. Almost all had previously given birth and had 3 living children, on average. The large majority (93\%) had previously used contraception, primarily injectables. One-quarter did not want additional children.

Cumulative probabilities of continuation and 95\% CI for each quarter by type of provider at enrollment and treatment group are presented in Table 2. Among women in the self-injection group, the continuation rate through 12 months of contraceptive use was not significantly different for women who received DMPA-SC selfinjection training from a CBP $[0.79$ (95\% CI, 0.70 to 0.86$)$ ] than those who received the training from a CHW [0.70 (95\% CI, 0.64 to 0.75)] $(P=.77)$. Though the continuation rates were much lower in the provider-administered group (the self-administered and provider-administered groups had 99 and 199 discontinuations, respectively), we did not find a significant difference between women who received DMPA-SC from a CBP $[0.48(95 \% \mathrm{CI}, 0.39$ to 0.57$)$ and those who received the method from a CHW $[0.44(95 \% \mathrm{CI}, 0.38$ to 0.50$)](P=.78)$. The incidence rate of discontinuation for those who received self-injection training from a $\mathrm{CHW}$ was 9 per 100 injection cycles (95\% CI, 7 to 11 ) compared with 6 per 100 injection cycles (95\% CI, 4 to 9) among those who were trained by a CBP. For the provider-administered group, the incidence rate for those who received DMPA-SC from a CHW was 21 per 100 injection cycles (95\% CI, 18 to 25$)$ compared with 19 per 100 injection cycles (95\% CI, 14 to 25 ) among those who received the method from a CBP.

The distribution of reasons for discontinuation did not differ significantly by provider type for selfinjectors $(P=.49)$ or for those in the provideradministered group $(P=.26)$. The most common reason for discontinuing was due to missing the reinjection window (data are reported elsewhere $^{11}$ ). Other reasons for discontinuing (in order of decreasing frequency) included loss to follow-up; by the woman's request, mostly related to side effects of DMPA-SC; and less commonly, by the provider's request for medical reasons. The reasons for discontinuation may underestimate the role of side effects during the trial. This is because after women discontinued, they were no longer counted in the estimates of side effect occurrence as the trial moved forward.

Data from pregnancy tests were incomplete due to refusals, loss to follow-up, and data 
TABLE 2. Cumulative Probability of Continuation Among Self-Administered and Provider-Administered Clients, Stratified by Type of Provider at Enrollment

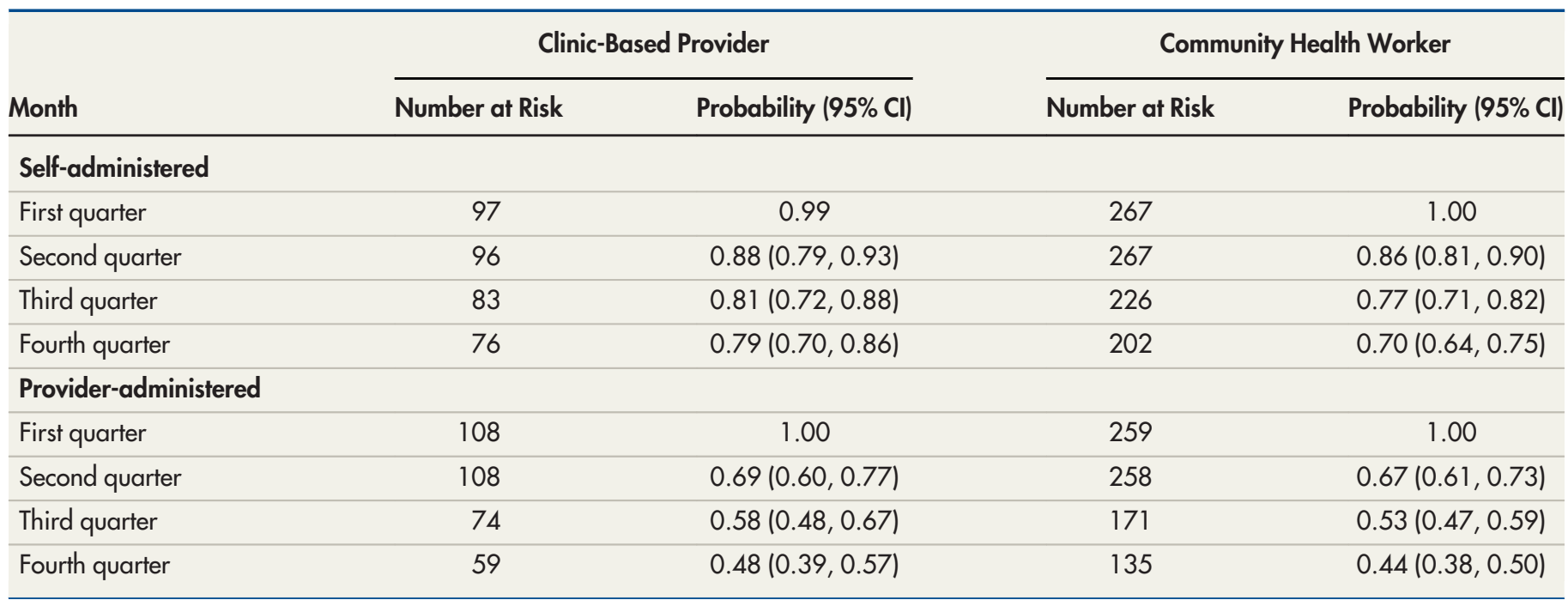

Abbreviation: $\mathrm{Cl}$, confidence interval.

collectors neglecting to administer a pregnancy test as planned (pregnancy status was unknown for $12 \%$ in the self-administered group and $21 \%$ in the provider-administered group). Among 612 women tested, 8 pregnancies were identified; 1 with a conception date prior to enrollment and 7 during follow-up. Of the 7 pregnancies, 3 occurred in the self-injection group ( 1 among CBP clients and 2 among CHW clients) and 4 in the provideradministered group ( 1 among CBP clients and 3 among CHW clients). Differences observed by type of provider within the self-injection group $(P>.99)$ and the provider-administered group $(P>.99)$ were not statistically significant.

The percentage of continuing women who experienced side effects decreased over time across all groups (Table 3 and Table 4). The differences in percentages of women experiencing side effects among those trained to self-inject by CBPs compared with those trained by CHWs were not statistically significant: 3 months$20 \%$ vs. $28 \% \quad(P=.21), 6$ months $-15 \%$ vs. $18 \% \quad(P=.74)$, and 9 months-12\% vs. $14 \%$ $(P=.70)$. Similarly, there were no statistically significant differences between those who received DMPA-SC from a CBP compared with a CHW: 3 months $-34 \%$ vs. $31 \%(P=.61), 6$ months$23 \%$ vs. $22 \%(P>.99)$, and 9 months-15\% vs. $19 \%(P=.69)$. Among women who reported side effects, the majority across all groups reported little to no effect on daily life.
Twenty related or possibly related adverse events were reported by 10 women in the selfadministration group (data not shown). Nine of these events were reported by 3 women who received self-injection training by CBPs and 11 of these events were reported by 7 women who received training by CHWs. These differences by type of provider were not statistically significant $(P=.73$ for the differences in proportion of women experiencing adverse events). Twentyeight related or possibly related adverse events were reported by 17 women in the provideradministered group (data not shown). Nine of these events were reported by 7 women who received DMPA-SC from CBPs and 19 of these events were reported by 10 women who received DMPA-SC from CHWs; these differences were not statistically significant $(P=.28$ for the differences in proportion of women experiencing adverse events). Furthermore, there were no significant differences between the groups in the types of adverse events reported. There were 5 serious adverse events reported during the trial by 4 different women. Two events related to DMPA-SC (menorrhagia and anemia requiring hospitalization) were reported by the same woman in the provider-administered group who was enrolled by a CHW and resolved without sequalae. The other serious adverse events, including 1 death (suspected liver cirrhosis), were unrelated to DMPA-SC.

\section{The percentage of women experiencing side effects were not significantly different by provider type.}


TABLE 3. Experience With Side Effects in Last 3 Months Among Self-Administered Participants, Stratified by Type of Provider at Enrollment, No. (\%)

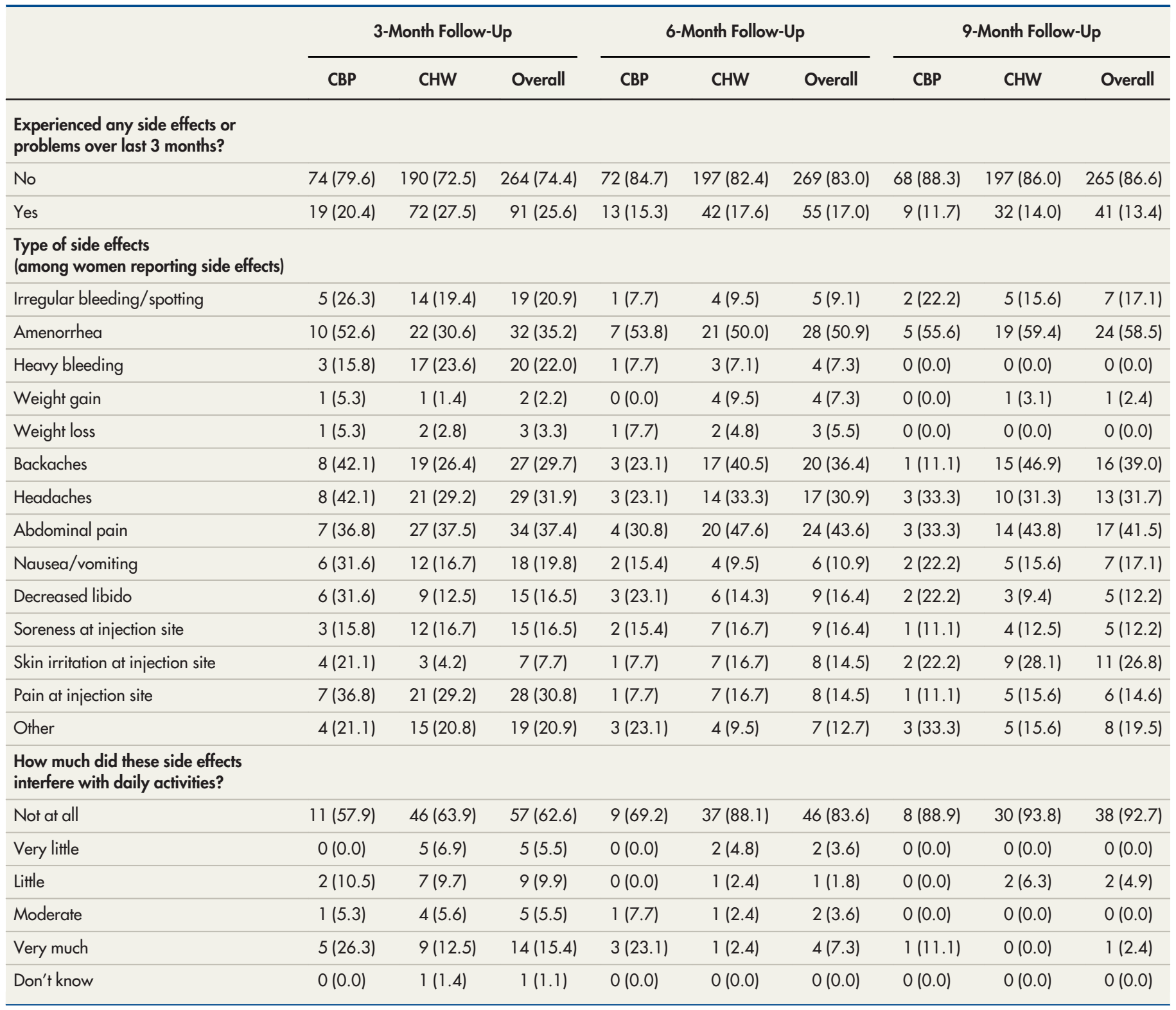

Abbreviations: CBP, clinic-based provider; CHW, community health worker; No., number.

The results of the Cox model are presented in Self-injectors were Table 5 . Only treatment group and health facility $\begin{array}{ll}\text { significantly less catchment site were statistically significant predic- } \\ \text { likely to } & \text { tors of continuation; therefore, no additional mul- }\end{array}$ likely to discontinue DMPA-SC than those who received it from providers. tivariable analyses were conducted. Consistent with the primary analysis reported elsewhere, we found that women in the self-injection group were significantly less likely to discontinue compared with women in the provider-administered group (hazard ratio, $0.43 ; P<.001$ ). Risk for discontinuation was also different among clinics $(P<.001)$.

\section{DISCUSSION}

Contraceptive continuation is important for reducing unintended pregnancies. This is one of the first studies to explore factors that affect continued use of DMPA-SC through 12 months, 
TABLE 4. Experience With Side Effects in Last 3 Months Among Provider-Administered Participants, Stratified by Type of Provider at Enrollment, No.(\%)

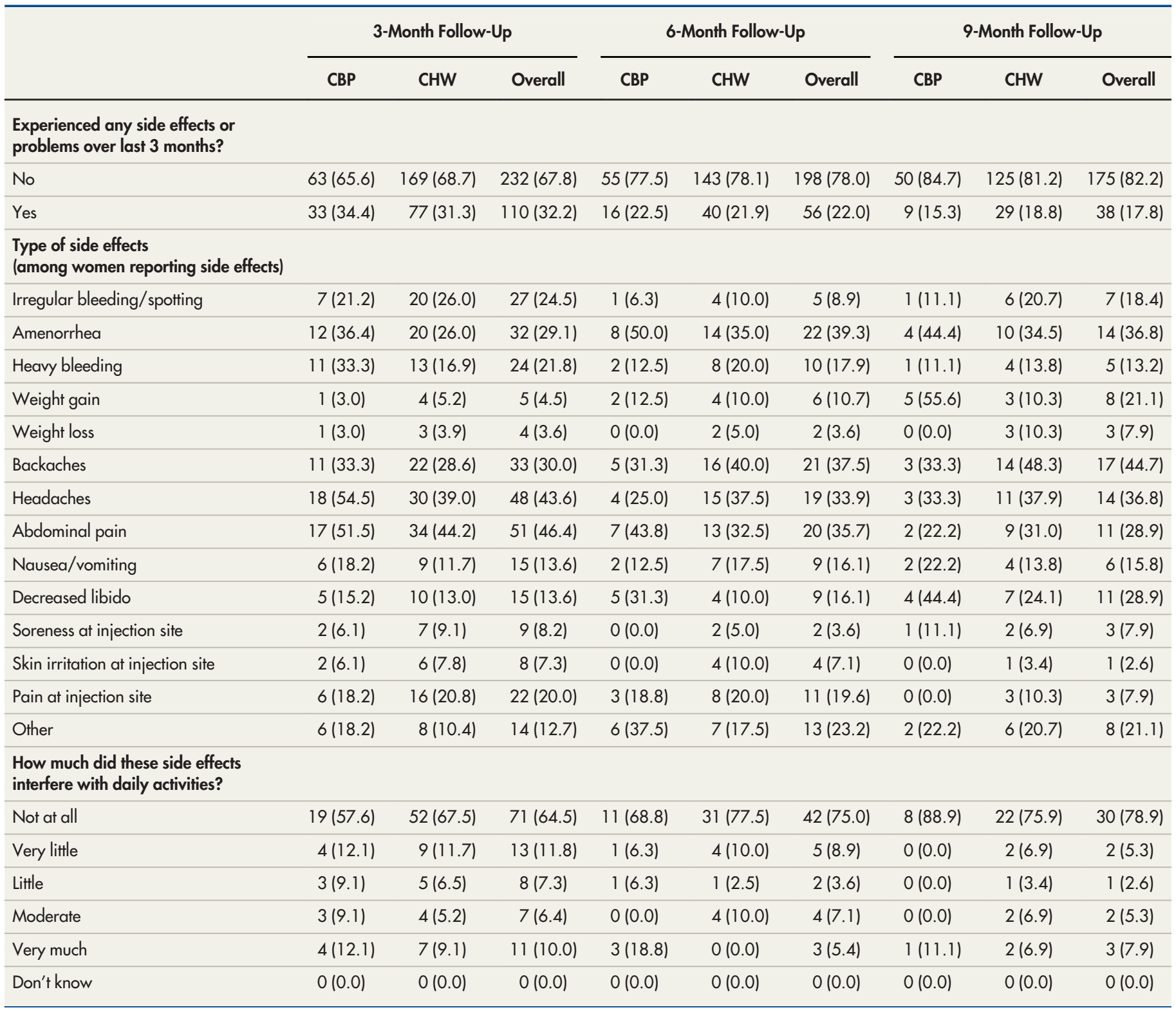

Abbreviations: CBP, clinic-based provider; CHW, community health worker; No., number.

including self-administered DMPA-SC. A retrospective study of 2015-2016 Demographic and Health Survey data in Malawi found a 12-month discontinuation rate of $41 \%$ for injectable contraceptive users. ${ }^{2}$ In this prospective trial, the discontinuation rates of DMPA-SC through 12 months were $52 \%$ and $56 \%$, for clients who received the injections from CBPs and CHWs, respectively. The discontinuation rates for self-injecting clients trained by CBPs and CHWs were substantially lower, $21 \%$ and $30 \%$, respectively. The differences in the continuation rates by provider type (CBPs and CHWs) were not statistically different for either self-administered or provider-administered DMPA-SC.

We did not find evidence that the type of provider influenced the risk of discontinuing, pregnancy, or safety, which suggests that CHWs-not only CBPs-can provide DMPA-SC or training on self-injection in low-resource settings without 
TABLE 5. Baseline Factors That May Influence DMPA-SC Discontinuation ( $N=731$ )

\begin{tabular}{lccc}
\hline Factor & Sample Size & PValue & Hazard Ratio (95\% CI) \\
\hline Self-administered vs. provider-administered & 364 vs. 367 & $<.001$ & $0.43(0.33,0.54)$ \\
\hline Age at enrollment & 731 & .18 & $0.98(0.96,1.01)$ \\
\hline Health facility catchment site $^{a}$ & 731 & $<.001$ & - \\
\hline Site 1 vs. Site 6 & 293 vs. 146 & - & $2.01(1.39,2.89)$ \\
\hline Site 2 vs. Site 6 & 67 vs. 146 & - & $1.78(1.09,2.91)$ \\
\hline Site 3 vs. Site 6 & 90 vs. 146 & - & $1.75(1.11,2.74)$ \\
\hline Site 4 vs. Site 6 & 75 vs. 146 & - & $2.90(1.88,4.47)$ \\
\hline Site 5 vs. Site 6 & 60 vs. 146 & - & $1.18(0.66,2.09)$ \\
\hline Married/regular sexual partner vs. none & 705 vs. 25 & .48 & $0.81(0.45,1.45)$ \\
\hline Worked outside home for pay in last 12 months vs. not & 96 vs. 634 & .18 & $1.25(0.90,1.72)$ \\
\hline Given birth vs. never given birth & 725 vs. 5 & .08 & $0.42(0.15,1.12)$ \\
\hline Completed primary school or higher vs. less or no school & 185 vs. 545 & .27 & $0.86(0.65,1.13)$ \\
\hline Christian, none, or other vs. Muslim & 418 vs. 311 & .10 & $1.24(0.96,1.61)$ \\
\hline Previous use of contraceptives vs. none or no response & 679 vs. 52 & .11 & $0.72(0.48,1.08)$ \\
\hline Previous use of injectables vs. none & 657 vs. 68 & .29 & $0.82(0.56,1.19)$ \\
\hline Community health worker vs. clinic-based provider & 526 vs. 205 & .45 & $0.90(0.68,1.19)$ \\
\hline
\end{tabular}

Abbreviations: Cl, confidence interval; DMPA-SC, subcutaneous depot medroxyprogesterone acetate; vs., versus.

a Sample size for each factor varied due to missing values.

b Except for site, the univariable models for all other factors were stratified by site.

\section{Permitting CHWs to train women on DMPA-SC self- injection could increase access to contraception and alleviate the work load of other providers.}

\section{Education levels} did not affect women's ability to self-inject. hampering continuation. Wait times at health facilities are often long and health facilities are often overcrowded and understaffed. Permitting CHWs to train women on DMPA-SC self-injection in community settings would enable women to circumvent the long lines and alleviate some of the work load at these health facilities. CHWs are based in rural and low-income areas where there is often high unmet family planning need, and they are more likely to remain in their communities once trained. ${ }^{33}$ In 2009, WHO concluded that CHWs can safely and effectively administer injectable contraceptives in non-clinical settings. ${ }^{34} \mathrm{CHW}$ provision of injectable contraception was once innovative but is now a standard of practice. Our results add to the body of evidence supporting task sharing and CHWs' potential to increase access to contraception and reduce unmet family planning needs, despite lower levels of training. ${ }^{6}$ Based on the evidence, self-administered and provider-administrated DMPA-SC should be scaled up in community settings using CHWs.

Of the factors explored, treatment group and health facility catchment site were the only factors that significantly influenced the risk of discontinuation, with self-injection leading to a reduced risk of discontinuation compared with provider administration. Consistent with previous studies of DMPA-IM, ${ }^{1,17,24,25}$ we did not find evidence that sociodemographic factors influenced DMPA-SC continuation. Importantly, we found that education levels did not affect women's ability to selfinject. Most women enrolled in the study had very little education and could inject on time and continue using DMPA-SC during the year-long trial.

Our findings are consistent with findings from nonrandomized prospective cohort studies in Senegal and Uganda, which observed that clients who self-injected DMPA-SC had a lower risk of discontinuing relative to clients who received DMPA-IM from CBPs. ${ }^{29,35}$ However, our findings differed from these studies in that they observed several other variables-some that we included in our model and some we did not-that influenced DMPA continuation. In Uganda, rural location and being younger increased discontinuation risk, whereas having a primary or greater education (versus no education), more children, and 
partner support for family planning increased continuation. In Senegal, paying for travel to the clinic and experiencing side effects increased discontinuation risk, whereas having more education, children, and household assets increased continuation. It may be that our site variable encompasses other underlying factors, such as rurality, which are not otherwise included in our model.

Our results are also similar to a study of provider-administered DMPA-SC in urban Nigeria that found no differences in continuation at 3 months according to the place women received DMPA-SC. ${ }^{36}$ In that study, data were collected from a convenience sample of users who obtained DMPA-SC from selected privatesector providers working in hospital, clinics, and retail drug outlets, as well as licensed Community Health Extension Workers. Unlike our study, the Nigeria study found differences in sociodemographic characteristics: women with some college education or more and those with 4 or more children were more likely to obtain another dose at 3 months. They also found that quality of counseling and side effects influenced continuation.

One limitation of our study is that women's reported outcomes may have been influenced by social desirability bias. Another challenge we faced was missing data for the pregnancy outcome. Given this, our pregnancy data should not be used for estimating the DMPA-SC failure rate. The study was also not designed to assess whether women with different characteristics or being assisted by various types of providers had different risks of discontinuation; therefore, the sample size for some of the comparisons may be too small to be conclusive. Furthermore, these are non-randomized comparisons and may be affected by selection biases. Lastly, there are numerous other variables and combinations of variables that we did not explore but which may influence continuation.

Although we did not find any of the sociodemographic factors associated with DMPA-SC discontinuation to help us target future efforts, the differences observed across sites may indicate the presence of other underlying factors that would be interesting to explore in future studies. For example, providers' management of clients who would like to continue using injectables but arrived late for their scheduled reinjections (although still within the grace period) has been documented to vary and to directly affect clients' continued use of contraception. ${ }^{37}$ Understanding the context and other characteristics of the populations served by these sites is important, but further exploration is not possible in our study due to our sample size and data contents. Despite the site differences, the positive effects of selfinjection were present in all sites, which speaks of the robustness of this finding across contexts and further supports our recommendations for scaling up DMPA-SC. Implementation challenges will need to be addressed to make this recommendation possible, including resources and planning for training and advanced provision of commodities for self-administration; however, the introduction and scale-up of this new evidence-based approach addresses the severe shortage of family planning providers and the persistent problem of DMPA discontinuation. We urge WHO and the global health community to expand their endorsements of CHW provision of injectables to include $\mathrm{CHW}$ provision of DMPA-SC for self-injection.

Acknowledgments: The FHI 360 project team included Ms. Leigh Wynne as the research utilization specialist, Dr. Kavita Nanda as medical monitor, Ms. Tomisha Turnage as research assistant, Ms. Kelly Feldman as budget analyst, Ms. Sophie Gao as supporting biostatistician, Ms. Angie Wheeless as randomization manager, Mr. Justin Dash as programmer, Ms. Jill Sergison as medical coder, and Dr. Lakshmi Venkatakrishnaiah as regulatory liaison. Drs. Kenneth Maleta, John Stanback, Donna McCarraher, Douglas Taylor, Laneta Dorflinger, and Timothy Mastro advised on this study, and Dr. Natasha Mack edited the manuscript. Ms. Tharniia Lalbahadur of SCT Consulting served as the clinical research monitor. In addition, special acknowledgment goes to the staff supporting this study from the University of Malawi College of Medicine and the Ministry of Health family planning providers in Mangochi District.

Funding: This work was made possible by the generous support of the American people through the U.S. Agency for International Development (USAID) and by the Children's Investment Fund Foundation (CIFF). The contents are the responsibility of $\mathrm{FHI} 360$ and do not necessarily reflect the views of USAID, the U.S. Government, or CIFF. Financial assistance was provided through the Advancing Partners \& Communities (APC) agreement funded by USAID under Agreement No. AID-OAA-A-1200047 , beginning October 1, 2012. APC is implemented by JSI Research \& Training Institute in collaboration with $\mathrm{FHI} 360$.

Competing Interests: None declared.

\section{REFERENCES}

1. Tsui AO, Brown W, Li Q. Contraceptive practice in Sub-Saharan Africa. Popul Dev Rev. 2017;43(suppl 1):166-191. CrossRef

2. National Statistical Office (NSO) of Malawi; ICF. Malawi Demographic and Health Survey 2015-16. Zomba, Malawi and Rockville, MD: NSO and ICF; 2017. https://dhsprogram.com/ pubs/pdf/FR319/FR319.pdf. Accessed February 1, 2019.

3. Rural population (\% of total population). The World Bank website. https://data.worldbank.org/indicator/SP.RUR.TOTL.ZS. Accessed July 10, 2018.

4. C-Change. Barriers to Family Planning Use in Malawi: Opportunities for Social and Behavior Change Communication. Washington, DC: C-Change; 2012. https://c-changeprogram.org/sites/default/ 
files/Barriers-to-Family-Planning-Use-Malawi.pdf. Accessed May 1 2018.

5. World Health Organization (WHO). Task Sharing to Improve Access to Family Planning/Contraception: Summary Brief. Geneva: WHO 2017. http://www.who.int/iris/handle/10665/259633. Accessed July 10, 2018.

6. High-Impact Practices in Family Planning (HIPs). Community Health Workers: Bringing Family Planning Services to Where People Live and Work. Washington, DC: US Agency for International Development; 2015. http://www.fphighimpactpractices.org/ briefs/community-health-workers. Accessed July 10, 2018.

7. FHI 360. Malawi: Monitoring and Evaluation of Community-Based Access to Injectable Contraception. Durham, NC: FHI 360; 2018. https://www.fhi360.org/sites/default/files/media/documents/ malawi-injectable-contraceptives.pdf. Accessed July 10, 2018.

8. Devlin K, Egan KF, Pandit-Rajani T. Community Health Systems Catalog Country Profile: Malawi. Arlington, VA: Advancing Partners \& Communities; 2016. https://www.advancingpartners.org/sites/ default/files/catalog/profiles/malawi_chs_catalog_profile_0.pdf. Accessed July 10, 2018.

9. Burke HM, Mueller MP, Packer C, et al. Provider acceptability of Sayana $\otimes$ Press: results from community health workers and clinicbased providers in Uganda and Senegal. Contraception. 2014; 89(5):368-373. CrossRef. Medline

10. Burke HM, Mueller MP, Perry B, et al. Observational study of the acceptability of Sayana $\otimes^{\circledR}$ Press among intramuscular DMPA users in Uganda and Senegal. Contraception. 2014;89(5):361-367. CrossRef. Medline

11. Burke HM, Chen $M$, Buluzi $M$, et al. Effect of self-administration versus provider-administered injection of subcutaneous depot medroxyprogesterone acetate on continuation rates in Malawi: a randomised controlled trial. Lancet Glob Health. 2018;6(5):e568e578. CrossRef. Medline

12. Cover J, Namagembe A, Tumusiime J, Lim J, Drake JK, Mbonye AK. A prospective cohort study of the feasibility and acceptability of depot medroxyprogesterone acetate administered subcutaneously through self-injection. Contraception. 2017;95(3):306-311. CrossRef. Medline

13. Cover J, Ba M, Lim J, Drake JK, Daff BM. Evaluating the feasibility and acceptability of self-injection of subcutaneous depot medroxyprogesterone acetate (DMPA) in Senegal: a prospective cohort study Contraception. 2017;96(3):203-210. CrossRef. Medline

14. Hubacher D, Goco N, Gonzalez B, Taylor D. Factors affecting continuation rates of DMPA. Contraception. 1999;60(6):345-351 CrossRef. Medline

15. Chhabra HK, Mohanty IR, Mohanty NC, Thamke P, Deshmukh YA. Impact of structured counseling on choice of contraceptive method among postpartum women. J Obstet Gynecol India. 2016; 66(6):471-479. CrossRef

16. Patron MC, Palabrica-Costello M. Knowledge, Attitudes and Practice of the DMPA Injectable Contraceptive: Data From Focus Group Discussions. Philippines. Final Report. Manila: Population Council's Asia and Near East Operations Research and Technical Assistance Project; 1995. http://citeseerx.ist.psu.edu/viewdoc/download? doi=10.1.1.175.7756\&rep=rep 1 \&type=pdf. Accessed February 2, 2019.

17. Population Council's Asia and Near East Operations Research and Technical Assistance Project. Focus on the Philippine DMPA reintroduction program: continuing users vs. drop-outs. Research News. 1996;7:1-2

18. Lei ZW, Chun Wu S, Garceau RJ, et al. Effect of pretreatment counseling on discontinuation rates in Chinese women given depomedroxyprogesterone acetate for contraception. Contraception. 1996;53(6):357-361. CrossRef. Medline
19. Riley AP, Stewart MK, Chakraborty J. Program- and method-related determinants of first DMPA use duration in rural Bangladesh. Stud Fam Plann. 1994;25(5):255-267. CrossRef. Medline

20. Cremer M, Ditzian L, April A, et al. Depot-medroxyprogesterone acetate contraception use among Salvadoran women: an in-depth analysis of attitudes and experiences. J Womens Health (Larchmt). 2011;20(1 1):1751-1756. CrossRef. Medline

21. Paul C, Skegg DCG, Williams S. Depot medroxyprogesterone acetate. Patterns of use and reasons for discontinuation. Contraception. 1997;56(4):209-214. CrossRef. Medline

22. Akbar J, Chakraborty J, Jahan N, Phillips JF, Satterwaite AP. Dynamics of depot medroxyprogesterone acetate (DMPA) use effectiveness in the Matlab Family Planning Health Services Project. Paper presented at: 7th Annual Contributors Conference of the Bangladesh Fertility Research Program; December 8-9, 1982; Dhaka, Bangladesh.

23. Sangi-haghpeykar H, Poindexter AN III, Bateman L, Ditmore JR. Experiences of injectable contraceptive users in an urban setting. Obstet Gynecol. 1996;88(2):227-233. CrossRef. Medline

24. Maslyanskaya S, Coupey SM, Chhabra R, Khan UI. Predictors of early discontinuation of effective contraception by teens at high risk of pregnancy. J Pediatr Adolesc Gynecol. 2016;29(3):269-275. CrossRef. Medline

25. Westfall JM, Main DS, Barnard L. Continuation rates among injectable contraceptive users. Fam Plann Perspect. 1996;28(6):275-277. CrossRef. Medline

26. MacLachlan E, Atuyame LM, Millogo T, et al. Continuation of subcutaneous or intramuscular injectable contraception when administered by facility-based and community health workers: findings from a prospective cohort study in Burkina Faso and Uganda. Contraception. 2018;98(5):423-429. CrossRef. Medline

27. Jain J, Jakimiuk AJ, Bode FR, Ross D, Kaunitz AM. Contraceptive efficacy and safety of DMPA-SC. Contraception. 2004;70(4):269275. CrossRef. Medline

28. Kaunitz AM, Darney PD, Ross D, Wolter KD, SperoffL. Subcutaneous DMPA vs. intramuscular DMPA: a 2-year randomized study of contraceptive efficacy and bone mineral density. Contraception. 2009;80(1):7-17. CrossRef. Medline

29. Cover J, Ba M, Drake JK, NDiaye MD. Continuation of self-injected versus provider-administered contraception in Senegal: a nonrandomized, prospective cohort study. Contraception. 2019;99 (2):137-141. CrossRef. Medline

30. Stanback J, Qureshi Z, Sekadde-Kigondu C, Gonzalez B, Nutley T. Checklist for ruling out pregnancy among family-planning clients in primary care. Lancet. 1999;354(9178):566. CrossRef. Medline

31. World Health Organization (WHO) Department of Reproductive Health and Research; Johns Hopkins Bloomberg School of Public Health/Center for Communication Programs (CCP), Knowledge for Health Project. Family Planning: A Global Handbook for Providers (2011 update). Baltimore, MD and Geneva: CCP and WHO; 2011. https://www.fphandbook.org/sites/default/files/ hb_english_2012.pdf. Accessed February 2, 2019.

32. World Health Organization (WHO). Selected Practice Recommendations for Contraceptive Use. 3rd ed. Geneva: WHO; 2016. http://www.who.int/reproductivehealth/publications/ family_planning/SPR-3/en/. Accessed September 27, 2017.

33. Family Planning 2020 (FP2020) Task Sharing Technical Working Group. Call to Action. Task Sharing to Increase Access to Contraception: A Proven Strategy That Makes A Difference. Washington, DC: FP2020; 2016. http://www. familyplanning2020. org/sites/default/files/Call-to-Action_ENGLISH_LTRformat_ 23June2016.pdf. Accessed February 2, 2019.

34. Stanback J, Spieler J, Shah I, Finger WR; Expanding Access to Injectable Contraceptives Technical Consultation Participants. Community-based health workers can safely and effectively 
administer injectable contraceptives: conclusions from a technical consultation. Contraception. 2010;81(3):181-184. CrossRef. Medline

35. Cover J, Namagembe A, Tumusiime J, Nsangi D, Lim J, NakigandaBusiku D. Continuation of injectable contraception when self-injected vs. administered by a facility-based health worker: a nonrandomized, prospective cohort study in Uganda. Contraception. 2018;98 (5):383-388. CrossRef. Medline
36. Liu J, Shen J, Diamond-Smith N. Predictors of DMPA-SC continuation among urban Nigerian women: the influence of counseling quality and side effects. Contraception. 2018;98(5):430-437. CrossRef. Medline

37. Baumgartner JN, Morroni C, Mlobeli RD, et al. Timeliness of contraceptive reinjections in South Africa and its relation to unintentional discontinuation. Int Fam Plan Perspect. 2007;33(2):66-74.

CrossRef. Medline

\section{Peer Reviewed}

Received: November 2, 2018; Accepted: January 16, 2019; First Published Online: March 20, 2019

Cite this article as: Burke HM, Chen $M$, Buluzi $M$, et al. Factors affecting continued use of subcutaneous depot medroxyprogesterone acetate (DMPA-SC): a secondary analysis of a 1-year randomized trial in Malawi. Glob Health Sci Pract. 2019;7(1):54-65. https://doi.org/10.9745/ GHSP-D-18-00433

(C) Burke et al. This is an open-access article distributed under the terms of the Creative Commons Attribution 4.0 International License (CC BY 4.0), which permits unrestricted use, distribution, and reproduction in any medium, provided the original author and source are properly cited. To view a copy of the license, visit http://creativecommons.org/licenses/by/4.0/. When linking to this article, please use the following permanent link: https:// doi.org/10.9745/GHSP-D-18-00433 